\title{
Effects of soaking period and gibberellic acid addition on caper seed germination
}

\author{
B. PASCUAL, A. SAN BAUTISTA, N. PASCUAL SEVA, R. GARCÍA MOLINA, \\ S. LÓPEZ-GALARZA AND J.V. MAROTO
}

Departamento de Producción Vegetal, ETSIA, Universidad Politécnica de Valencia, Camino de Vera 14, 46020 Valencia, Spain (E-mail: bpascual@prv.upv.es)

(Accepted July 2008)

\section{Summary}

In order to improve caper seed germination, this two-year study (2005-2006) was designed to determine the effects of seed soaking treatments and soaking times, individually or in combination with the addition of gibberellic acid to the germination substrate. Besides testing the control seeds, 7 soaking periods were assayed, soaking seeds in tap water at room temperature for $24 \mathrm{~h}, 15,30,45,60,75$ and 90 days. Germination tests were performed in closed Petri dishes in a growth chamber. Germination data were fitted to the logistic function and calculations were made for the maximum germination percentage, the time to reach $50 \%$ of final germination and the mean relative cumulative rate. A soaking period of 30 days or longer enhanced seed germination; final germination values ranged from 95 to $99 \%$, reducing the time to reach $50 \%$ of final germination and consequently the duration of germination tests. Addition of gibberellic acid to the substrate after soaking improved germination only for control seeds and those soaked for $24 \mathrm{~h}$ or 15 days. Seed soaking for 30 or 45 days, followed or not by the addition of a gibberellic acid solution to the substrate, is an efficient method to enhance caper seed germination.

\section{Introduction}

Caper (Capparis spinosa L.) is a suffruticose winter-deciduous plant of the Capparidaceae family. It is considered as a ruderal of Mediterranean climates and is cultivated mainly in Mediterranean regions. The flower buds of this shrub have been used for distinct purposes since ancient times (Rodrigo et al., 1992; Matthäus and Özcan, 2002). Recently studies have reported on the properties and potential uses of its flower buds (capers), fruits (caperberries), seeds, young shoots and roots as food and medicine (Akgül and Özcan, 1999; Inocencio et al., 2000; Giuffrida et al., 2002; Rivera et al., 2003; Özcan and Aydin, 2004; Yili et al., 2006). Other studies have focused on the phytopathological use of the plant extracts (Al-Banna et al., 2003; Mansour et al., 2004). Global demand for these products has increased, but the poor germination of caper seeds in field conditions greatly restricts the expansion of this crop (Pascual et al., 2006).

In a previous study (Pascual et al., 2003) caper seed germination was examined, considering the influence of fruit weight, position on the mother plant and maturation stage. A later study (Pascual et al., 2006) dealt with germination behaviour during seed 
storage. Research was also carried out (Pascual et al., 2004) to determine an efficient method for ensuring satisfactory seed germination, assaying two types of treatments, individually or in combination: 1) treatments to overcome hardseededness (mechanical scarification with sandpaper, mechanical scarification with ultrasound, acid scarification, hot water scarification, enzymatic scarification, seed soaking in water for $24 \mathrm{~h}$ ); 2) treatments to break physiological dormancy [solutions of potassium nitrate or gibberellic acid (GA)]. In this 2004 study, it was concluded that adding a GA solution to the substrate (filter paper) after acid scarification is a simple and effective method to ensure satisfactory seed germination. Acid scarification can be substituted for mechanical scarification with ultrasound, hot water scarification or soaking, but these procedures need more time to obtain satisfactory germination levels. Soaking for $24 \mathrm{~h}$ has proved to be useful to remove hardseededness, and it is also the most practical treatment among those tested.

By analysing germination curves, the present study aimed to improve seed germination by soaking seeds [to remove hardseededness through coat softening (Hartmann et al., 2002)] in water for long periods, individually or in combination with a GA treatment to break physiological dormancy (Hartmann et al., 2002).

\section{Materials and methods}

Two experiments were conducted at the Universidad Politécnica de Valencia (Valencia, Spain), the first in 2005 and the second in 2006. For the 2005 experiment, forty ripe fruits were collected on September $1^{\text {st }}$, before dehiscence, from five three-year-old plants of cultivar Común, grown in Valencia (Spain). Seeds were extracted, rinsed in tap water and dried at room temperature for two days. Mature dark-brown seeds were selected, rejecting light seeds which floated in tap water as well as seeds measuring less than $2 \mathrm{~mm}$ in length. Selected seeds were stored in closed plastic cans at $7 \pm 0.5^{\circ} \mathrm{C}$ until needed.

In addition to testing control seeds, seeds were soaked in $0.1 \mathrm{~L}$ tap water at room temperature for 15 days, individually or in combination with a GA treatment, which consisted in adding a $500 \mathrm{mg} \mathrm{L}^{-1} \mathrm{GA}_{3}$ (AG-100 L.S.) solution to saturate the test substrate.

The 15 -day and $24 \mathrm{~h}$ soaking treatments started on October $3^{\text {rd }}$ and $17^{\text {th }} 2005$, respectively, and germination tests on October $18^{\text {th }} 2005$. To prevent fungal infection, seeds were surface sterilized for $10 \mathrm{~min}$ in sodium hypochlorite, rinsed twice in tap water and once more in distilled water.

Germination tests were performed in closed 9-cm Petri dishes $(\varnothing 9 \mathrm{~cm})$ between two layers of filter paper Whatman No.1 (ISTA, 1999) moistened with distilled water, or $500 \mathrm{ppm}$ GA solution to saturate the substrate, to which $250 \mathrm{ppm}$ carbendazim was added to prevent fungal development. Samples consisted of 400 seeds (four replications of 100 seeds each). Petri dishes were placed in a growth chamber (model Climatronic) under alternating temperature and light: $12 \mathrm{~h}$ at $20 \pm 1{ }^{\circ} \mathrm{C}$ in the dark and $12 \mathrm{~h}$ at $30 \pm 1{ }^{\circ} \mathrm{C}$ under a photosynthetic photon flux density of $324 \mu \mathrm{mol} \mathrm{m}^{-2} \mathrm{~s}^{-1}$ for a maximum of 100 days. Seeds were considered germinated when the primary root protruded from the seed coat. Assays were considered satisfactory only when the difference between the maximum 
and the minimum germination percentage of the four replications was not higher than the tolerance level indicated in the International Rules for Seed Testing (ISTA, 1999). It was not necessary to repeat any assay.

Based on the results obtained in the 2005 experiments, eighty ripe fruits were collected on September $1^{\text {st }}, 2006$, before dehiscence, from the same experimental plants used in 2005. Seeds were extracted, selected and stored as described previously. In 2006, seven soaking periods were assayed: $24 \mathrm{~h}, 15,30,45,60,75$ and 90 days, being both soaking treatments and germination tests conducted as in 2005. Soaking treatments (1590 days) started on October $2^{\text {nd }} 2006$ and each germination test started at the end of the corresponding soaking period. Germination tests of control and seeds soaked for $24 \mathrm{~h}$ were initiated on the same day as those of the 15-day soaking period (October 17 ${ }^{\text {th }} 2006$ ).

The design in 2005 was a $2 \times 2$ factorial (soaking and control $\times$ distilled water and GA solution to saturate the substrate). In 2006 the design was an $8 \times 2$ factorial (7 soaking periods and control $\times$ distilled water and GA solution to saturate the substrate).

Germination data of each replicate were fitted to the logistic function $G=A[1+$ $\exp (\beta-k t)]^{-1}$ (Torres and Frutos, 1989; Pascual et al., 2003) defined as a special case of the Richards' function (Causton and Venus, 1981), where $G=$ cumulative germination $(\%) ; t=$ germination time (days); $A=$ final germination percentage; $\beta$ and $k$ are function parameters. Derived quantities with biological significance were calculated, as were the time in days to reach $50 \%$ of final germination percentage $(G t 50=\beta / k)$ and the mean relative cumulative germination rate $\left(k / 2\right.$, days $\left.^{-1}\right)$. Variables $(A, \beta, k / 2$, and Gt 50$)$ were analysed by SAS analysis of variance (SAS Institute, 1989). Percentage data were arcsin transformed before analysis. A probability of $\leq 5 \%$ was considered significant. Mean separations were performed, when appropriate, using the least significant difference (LSD) at $P \leq 0.05$.

\section{Results}

In the 2005 experiment, the coefficients of determination $\left(\mathrm{R}^{2}\right)$ for 16 curves (four replicates from four combinations of variation sources) were higher than 0.974 , with $\mathrm{F}$ ratio values of the model statistically significant $(P \leq 0.01)$, whilst in the 2006 experiment, the $\mathrm{R}^{2}$ for 64 curves (four replicates from sixteen combinations of variation sources) ranged from 0.923 to 0.998 . In both years, $F$ ratio values of the model were statistically significant $(P \leq 0.01)$ (data not included). Therefore, the logistic function is suitable to analyse caper seed germination in these experiments, and it allows for the utilization of the variable $A$ (instead of $G$ ) as well as other variables such as $\beta$ and $k$.

Figure 1 shows the fitted curves corresponding to the values of each treatment combination for the 2005 experiment. The highest $A$ values and the most rapid germination were obtained when soaked seeds were germinated in the substrate moistened in the GA solution.

Variables $A$ and $\beta$ (which places the curve in relation to the time axis, without any biological significance) were affected $(P \leq 0.01)$ by both types of treatment (table 1$)$ and the corresponding interaction was no significant $(P \leq 0.01)$. The $A$ value for control seeds 


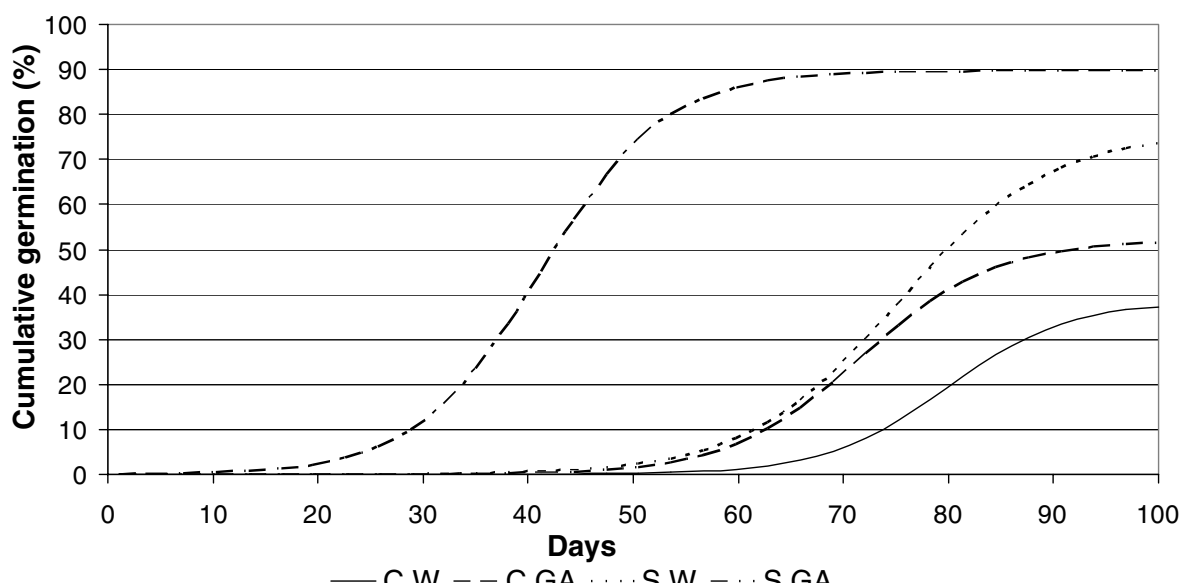

Figure 1. Logistic model fitted to cumulative germination curves of caper seeds obtained in 2005. Values for treatments of seed soaking and gibberellic acid solution addition to the substrate, individually or in combination. $\mathrm{C}$, control; S, soaking for 15 days; $\mathrm{W}$, water addition to the substrate; GA, gibberellic acid solution addition to the substrate.

Table 1. Influence of treatments for satisfactory seed germination [T 1: Seed soaking; T 2: Adding water or gibberellic acid (GA) solution to the test substrate] on values of $A$ and variables $\beta, k / 2$ and $G t 50$ of germinated caper. Experiment carried out in 2005.

\begin{tabular}{|c|c|c|c|c|c|}
\hline Treatment & & $A$ & $\beta$ & $k / 2$ & Gt 50 \\
\hline \multirow[t]{2}{*}{ T 1} & Control (C) & $45.25 \mathrm{~b}$ & $12.59 \mathrm{a}$ & $0.0829-$ & $76.17 \mathrm{a}$ \\
\hline & Soaking (S) & $82.86 \mathrm{a}$ & $8.70 \mathrm{~b}$ & $0.0770-$ & $58.33 \mathrm{~b}$ \\
\hline \multirow[t]{2}{*}{ Т 2} & Water (W) & $57.23 \mathrm{~b}$ & $12.11 \mathrm{a}$ & $0.0779-$ & $77.90 \mathrm{a}$ \\
\hline & GA (GA) & $70.88 \mathrm{a}$ & $9.17 \mathrm{~b}$ & $0.0820-$ & $56.60 \mathrm{~b}$ \\
\hline \multirow[t]{5}{*}{$\mathrm{T} 1 \times \mathrm{T} 2$} & $\mathrm{C} \mathrm{W}$ & 39.42 & 13.81 & 0.0865 & 80.53 \\
\hline & C GA & 52.08 & 11.37 & 0.0793 & 71.81 \\
\hline & S W & 76.03 & 10.42 & 0.0693 & 75.27 \\
\hline & S GA & 89.69 & 6.98 & 0.0848 & 41.39 \\
\hline & $\operatorname{LSD}(P \leq 0.05)$ & --- & --- & --- & 5.70 \\
\hline \multicolumn{6}{|c|}{ Analysis of variance } \\
\hline Source & (d.f.) & \multicolumn{4}{|c|}{$\mathrm{F}$ ratio } \\
\hline $\mathrm{T} 1$ & (1) & $77.85 * *$ & $31.80 * *$ & $0.92^{\mathrm{NS}}$ & $92.82 * *$ \\
\hline T 2 & (1) & $10.27 * *$ & $18.12 * *$ & $0.46^{\mathrm{NS}}$ & $132.43 * *$ \\
\hline $\mathrm{T} 1 \times \mathrm{T} 2$ & (1) & $0.00^{\mathrm{NS}}$ & $0.53^{\mathrm{NS}}$ & $3.47^{\mathrm{NS}}$ & $46.17 * *$ \\
\hline
\end{tabular}

Means in columns followed by different letters differ significantly at $P \leq 0.05$ using LSD test.

Ns and $* *$ indicates not significant or significant at $P \leq 0.01$, respectively. 
can be considered adequate (39.4\%). Both soaking and GA addition increased $A$ and reduced $\beta$ values. The variable $\beta / k$ [Gt 50, which represents the time (days) to reach $50 \%$ of the final germination percentage] was also affected $(P \leq 0.01)$ by the two treatments and both decreased the $\beta / k$ values, but the corresponding interaction was significant $(P \leq 0.01)$. On analysing this interaction, it was observed that the reduction in $\beta / k$ values triggered by the GA addition was greater for soaked seeds (reduced from 75.3 to $41.4 \%$ ) than for control seeds (reduced from 80.5 to $71.8 \%$ ).

Figure 2 shows the fitted curves corresponding to the average values of soaking treatments for the 2006 experiment (A: water addition; B: GA addition). GA addition to the substrate and soaking periods of 30 days or longer increased $A$ values and triggered a faster germination.
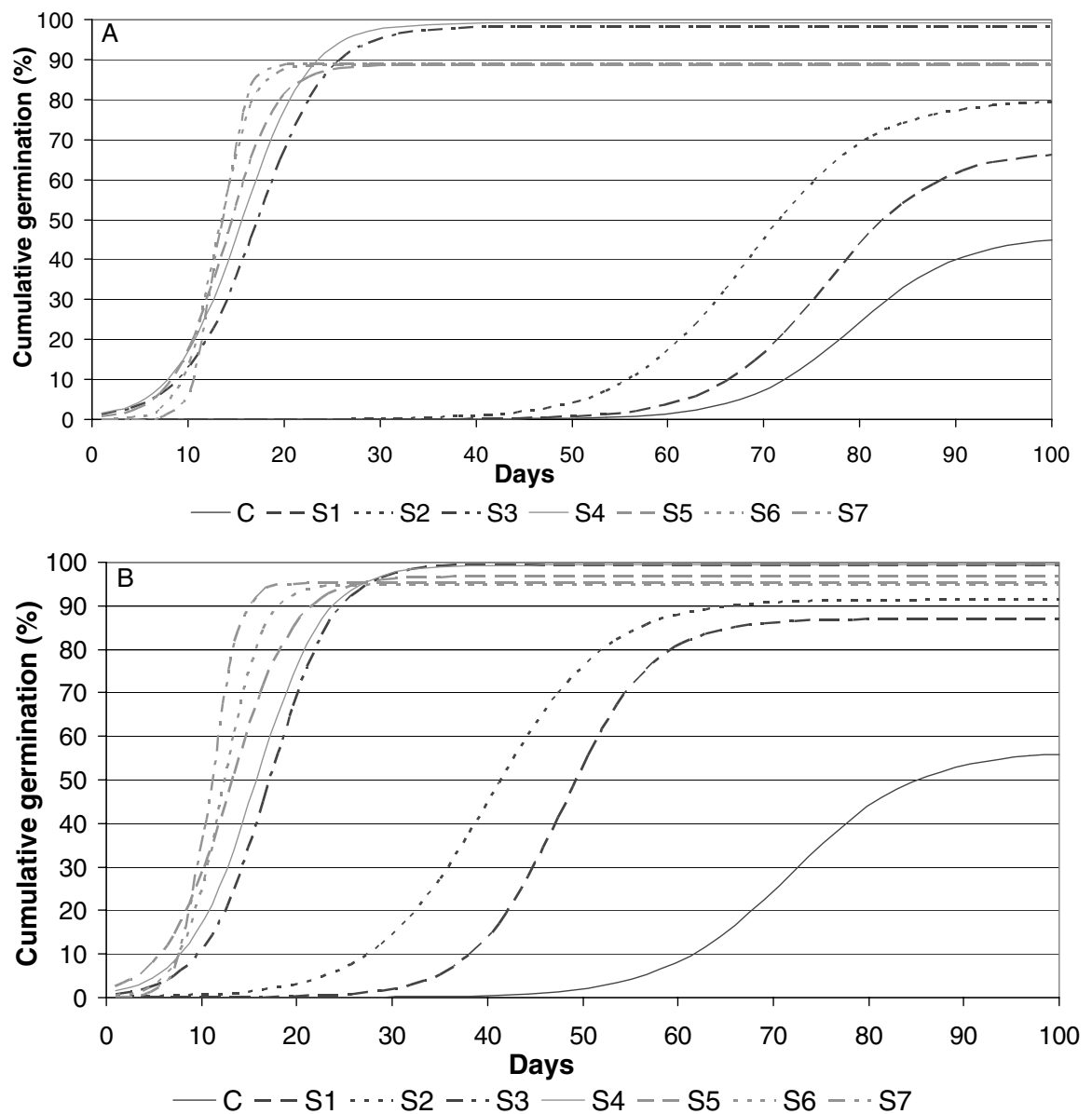

Figure 2. Logistic model fitted to cumulative germination curves of caper seeds obtained in 2006. A, values for soaking treatments with water addition to the substrate; B, values for soaking treatments with gibberellic acid solution addition to the substrate. In both figures: C, control; S1, S2, S3, S4, S5, S6 and S7 correspond to soaking periods of $24 \mathrm{~h}, 15,30,45,60,75$ and 90 days, respectively. 
Table 2. Influence of treatments for satisfactory seed germination [T 1: Seed soaking; T 2: Adding water or gibberellic acid (GA) solution to the test substrate] on values of $A$ and variables $\beta, k / 2$ and $G t 50$ of germinated caper. Experiment carried out in 2006.

\begin{tabular}{|c|c|c|c|c|c|}
\hline Treatment & & $A$ & $\beta$ & $k / 2$ & Gt 50 \\
\hline \multirow[t]{8}{*}{$\mathrm{T} 1$} & Control (C) & $51.41 \mathrm{e}$ & $12.41 \mathrm{a}$ & $0.0817 \mathrm{~d}$ & $75.76 \mathrm{a}$ \\
\hline & $\mathrm{S} 1$ & $77.25 \mathrm{~d}$ & $11.71 \mathrm{a}$ & $0.0965 \mathrm{~d}$ & $63.20 \mathrm{~b}$ \\
\hline & $\mathrm{S} 2$ & $85.69 \mathrm{c}$ & $8.66 \mathrm{~b}$ & $0.0802 \mathrm{~d}$ & $55.07 \mathrm{c}$ \\
\hline & $\mathrm{S} 3$ & $98.90 \mathrm{a}$ & $4.84 \mathrm{~d}$ & $0.1414 \mathrm{c}$ & $17.20 \mathrm{~d}$ \\
\hline & S4 & $99.27 \mathrm{a}$ & $4.42 \mathrm{~d}$ & $0.1414 \mathrm{c}$ & $15.60 \mathrm{~d}$ \\
\hline & S5 & $92.74 \mathrm{~b}$ & $4.57 \mathrm{~d}$ & $0.1703 \mathrm{c}$ & $13.42 \mathrm{~d}$ \\
\hline & S6 & $91.81 \mathrm{~b}$ & $6.83 \mathrm{c}$ & $0.2708 \mathrm{~b}$ & $12.72 \mathrm{~d}$ \\
\hline & S7 & $92.04 \mathrm{~b}$ & $9.35 \mathrm{~b}$ & $0.3861 \mathrm{a}$ & $12.03 \mathrm{~d}$ \\
\hline \multirow[t]{2}{*}{ Т 2} & Water (W) & $82.15 \mathrm{~b}$ & $8.90 \mathrm{a}$ & $0.1797 \mathrm{a}$ & $37.41 \mathrm{a}$ \\
\hline & $\mathrm{GA}(\mathrm{GA})$ & 89.78 a & $6.81 \mathrm{~b}$ & $0.1624 \mathrm{~b}$ & $28.45 \mathrm{~b}$ \\
\hline \multirow[t]{17}{*}{$\mathrm{T} 1 \times \mathrm{T} 2$} & $\mathrm{C} \mathrm{W}$ & 46.06 & 14.04 & 0.0884 & 79.64 \\
\hline & C GA & 56.76 & 10.77 & 0.0750 & 71.87 \\
\hline & $\mathrm{S} 1 \mathrm{~W}$ & 67.47 & 13.21 & 0.0864 & 78.45 \\
\hline & S1 GA & 87.03 & 10.20 & 0.1066 & 47.94 \\
\hline & S2 W & 79.94 & 10.73 & 0.0785 & 69.60 \\
\hline & $\mathrm{S} 2 \mathrm{GA}$ & 91.45 & 6.59 & 0.0819 & 40.55 \\
\hline & S3 W & 98.21 & 4.63 & 0.1354 & 17.26 \\
\hline & S3 GA & 99.60 & 5.05 & 0.1474 & 17.13 \\
\hline & S4 W & 99.17 & 4.47 & 0.1435 & 15.61 \\
\hline & S4 GA & 99.36 & 4.37 & 0.1393 & 15.60 \\
\hline & S5 W & 88.73 & 5.26 & 0.1905 & 13.82 \\
\hline & S5 GA & 96.75 & 3.89 & 0.1500 & 13.01 \\
\hline & S6 W & 88.72 & 7.73 & 0.2978 & 13.05 \\
\hline & S6 GA & 94.89 & 5.93 & 0.2439 & 12.39 \\
\hline & S7 W & 88.91 & 11.01 & 0.4170 & 13.20 \\
\hline & S7 GA & 95.17 & 7.68 & 0.3551 & 10.85 \\
\hline & $\operatorname{LSD}(P \leq 0.05)$ & 8.48 & 1.46 & --- & 7.49 \\
\hline
\end{tabular}

Analysis of variance

Source

(d.f.)

F ratio

\begin{tabular}{|c|c|c|c|c|c|}
\hline $\mathrm{T} 1$ & (7) & $28.55^{* *}$ & $65.62 * *$ & $4.65^{*}$ & $45.78^{* *}$ \\
\hline Т 2 & (1) & $55.55^{* *}$ & $77.51 * *$ & $88.48^{* *}$ & $206.48^{* *}$ \\
\hline $\mathrm{T} 1 \times \mathrm{T} 2$ & (7) & $2.12 *$ & $5.13 * *$ & $1.87^{\mathrm{NS}}$ & $12.42 * *$ \\
\hline
\end{tabular}

S1, S2, S3, S4, S5, S6, S7 correspond to soaking periods of $24 \mathrm{~h}, 15,30,45,60,75$ and 90 days, respectively. Means in columns followed by different letters differ significantly at $P \leq 0.05$ using LSD test.

Ns, $*$ and $* *$ indicates not significant or significant at $P \leq 0.05$ and $P \leq 0.01$, respectively. 
Both soaking period and GA addition affected variable $A(P \leq 0.01$; table 2$)$, being significant the corresponding interaction $(P \leq 0.05)$. The lowest value for the soaking period corresponded to control seeds $(51.4 \%)$ and the highest values to 30 or 45 day soaking periods (a figure on the order of 99\%); GA addition increased the average $A$ values from 82.2 to $89.8 \%$. On analysing this interaction, it was observed that the GA addition significantly increased $A$ values only for non soaked seeds and those soaked for $24 \mathrm{~h}$ and 15 days. With 30-day or longer soaking periods, followed by GA addition to the substrate, the obtained $A$ values ranged from 95 to $99 \%$. Without adding GA, $A$ values ranged from 98 to $99 \%$ for 30 - or 45 -day soaking periods, whilst for 60-90 day soaking periods, $A$ values were lower than $90 \%$.

The function parameter $\beta$ was affected $(P \leq 0.01)$ by both soaking period (the lowest average values were those of soaking periods of 30, 45 and 60 days, and the highest values corresponded to non soaked seeds and those soaked for $24 \mathrm{~h}$ ) and GA addition (reducing the average $\beta$ values from 8.9 to 6.8 ), being significant the corresponding interaction $(P \leq 0.01$; table 2$)$. The study of this interaction reveals that GA addition reduced $\beta$ values only for non soaked seeds and those soaked for $24 \mathrm{~h}, 15,75$ or 90 days, but not for seeds soaked for 30,45 or 60 days, i.e. the soaking periods that had the lowest average values.

The mean relative cumulative germination rate $(k / 2)$ was affected by both duration of the soaking period $(P \leq 0.05$; the highest average values corresponding to 90 days followed by 75 days, whilst the lowest average values corresponded to control seeds and soaking periods of 30 and 15 days) and addition of GA to the substrate $(P \leq 0.01$; the highest average values corresponding to water addition). The interaction did not result significant (table 2).

The variable $\beta / k$ (Gt 50) was affected $(P \leq 0.01$; table 2$)$ by both seed soaking period [the highest mean value corresponding to non soaked seeds (75.8 days) followed by $24 \mathrm{~h}$ (63.2 days) and then 15 days (55.1 days)] and GA addition [the lowest mean value corresponding to GA addition (28.5 days)]. The corresponding interaction was significant $(P \leq 0.01)$. The GA addition reduced $\beta / k$ values only for non soaked seeds and those soaked for $24 \mathrm{~h}$ or 15 days, but not for seeds soaked for longer periods, which were the soaking periods that yielded the lowest average $\beta / k$ values.

\section{Discussion}

Results confirm that the use of the logistic function is suitable for analysing caper seed germination as shown in earlier studies of caper (Pascual et al., 2003; Pascual et al., 2004; Pascual et al., 2006) as well as in similar studies of other crops (Torres and Frutos, 1990; Tei and Ciriciofolo, 1997; Hara, 1999; Cheng and Gordon, 2000).

In the 2005 and 2006 experiments, final germination values for control seeds $( \pm 39$ $46 \%$ ) were higher than those reported previously (28\%; Pascual et al., 2004). This is probably due to short period of time between fruit harvest and the beginning of the 2005 and the 2006 experiments (one month). As reported in this 2004 study, long time periods are required to reach $50 \%$ of final germination (a figure on the order of 80 days). 
Seed soaking for a $24 \mathrm{~h}$ period increased $A$ values without reducing Gt 50, in agreement with previously published results (Pascual et al., 2004). Seed germination was enhanced with soaking periods up to 45 days and then decreased with longer ones. Soaking periods of 30-45 days lead to very high final germination levels (98-99\%), greater than the maximum values cited in the literature (48\% in Yildirim, 1998; 53\% in Tansi, 1999; 68\% in Sozzi and Chiesa, 1995; above 50\% in Rinaldelli, 2000) and higher than the $80 \%$ obtained by Orphanos (1983). With 30-90-day soaking periods, Gt 50 values were reduced to 13-17 days, which means that it is possible to reduce the duration of germination tests to 35 days in the case of the 30-day soaking period or 25 days for the 75-day and 90-day soaking periods. These germination test times are similar or shorter than the total time of incubation normally used in the previously cited studies (30 days in Sozzi and Chiesa, 1995; 60 days in Tansi, 1999; 60 days in Rinaldelli, 2000). Thus, soaking seeds in water for long periods improves caper seed germination, since the coat is softened and hardseededness overcome.

GA addition to the substrate increased $A$ values $(P \leq 0.05)$ and reduced $\beta$ and $G t 50$ values $(P \leq 0.01)$ only in cases when the lowest germination percentages were observed for non GA addition treatment (mainly control and seeds soaked for $24 \mathrm{~h}$ and 15 days), but it did not affect any of these three parameters $(P \leq 0.05)$ for better germination cases, i.e. 30, 45 or 60 days. These results agree with those reported by Rinaldelli (2000) who concluded that treatment with gibberellins can facilitate germination, eliminating impediments for germination which remain even after destruction of the coat by sulphuric acid. As discussed by Rinaldelli (2000) and Pascual et al. (2004), both types of treatments to overcome physical and physiological dormancy exert an additive effect, so gibberellins can enhance seed germination when its value is relatively low, but it is impossible to enhance it when its value is practically $100 \%$.

In conclusion, these experiments have successfully tested a simple and efficient method for breaking seed dormancy and enhancing seed germination of caper. This method involves extending the time seeds are soaked in water and then adding a GA solution to the germination substrate. With 30-day and 45-day soaking periods, it is not necessary to add a GA solution to the germination substrate. Thus, treatments are simplified in terms of time, materials and labour.

Taking into account the differences observed in the final germination percentages obtained with control seeds in 2005 and 2006 in relation those reported in earlier experiments (Pascual et al., 2004), future experiments will continue to study the influence of the time between fruit harvest and the beginning of germination tests. Much more research is needed to determine the causes for caper seed dormancy, particularly, the influence of the hormonal balance.

\section{References}

Akgül, A. and Özcan, M. (1999). Some compositional characteristics of caper (Capparis spp.) seed and oil. Grasas y Aceites, 50, 49-52.

Al-Banna, L., Darwish, R.M. and Aburjai, T. (2003). Effect of plant extract and essential oils on root-knot nematode. Phytopathologia Mediterranea, 42, 123-128. 
Causton, D.R. and Venus, J.C. (1981). Single leaf growth and the Richards function: methodology. In The Biometry of Plant Growth. (ed. D.R. Causton and J.C. Venus), pp. 87-143. Edward Arnold, London.

Cheng, C.H. and Gordon, I.L. (2000). The Richards function and quantitative analysis of germination and dormancy in meadowfoam (Limanthes alba). Seed Science Research, 10, 265-277.

Giuffrida, D., Salvo, F., Ziino, M., Toscano G. and Dugo, G. (2002). Initial investigation on some chemical constituents of capers (Capparis spinosa L.) from the island of Salina. Italian Journal of Food Science, 14, 25-33.

Hara, Y. (1999). Calculation of population parameters using Richards function and application of indices of growth and seed vigour to rice plants. Plant Production Science, 2, 129-135.

Hartmann, H.T., Kester, D.E., Davies, F.T. and Geneve R.L. (2002). Hartmann and Kester's Plant propagation. Principles and Practices. Prentice Hall, New Jersey.

Inocencio, C., Rivera, D. and Alcaraz, F. (2000). Flavonoid contents of commercial capers (Capparis spinosa, C. sicula and C. orientalis) produced in Mediterranean countries. European Food Research and Technology, 212, 70-74.

International Seed Testing Association (1999). International Rules for Seed Testing. Rules 1999. Seed Science and Technology, 27, Supplement.

Mansour, F., Azaizeh, H., Saad, B., Tadmor, Y., Abo-Moch, F. and Said, O. (2004). The potencial of Middle Eastern flora as a source of new safe bio-acaricides to control Tetranychus cinnabarinus, the carmine spider mite. Phytoparasitica, 32, 66-72.

Matthäus, B. and Özcan, M. (2002). Glucosinolate composition of young shoots and flower buds of Capers (Capparis species) growing wild in Turkey. Journal of Agricultural and Food Chemistry, 50, 7323-7325.

Orphanos, P.I. (1983). Germination of caper (Capparis spinosa L.) seeds. Journal of Horticultural Science, $\mathbf{5 8}$, 267-270.

Özcan, M. and Aydin, C. (2004). Physico-mechanical properties and chemical analysis of raw and brined caperberries. Biosystems Engineering, 89, 521-524.

Pascual., B., San Bautista, A., Ferreros, N., López-Galarza, S. and Maroto, J.V. (2003). Analysis of germination of caper seeds as influenced by the position of fruit on the mother plant, fruit maturation stage and fruit weight. Journal of Horticultural Science and Biotechnology, 78, 73-78.

Pascual, B., San Bautista, A., Imbernón, A., López-Galarza, S., Alagarda, J. and Maroto, J.V. (2004). Seed treatments for improved germination of caper (Capparis spinosa L.). Seed Science and Technology, 32, 637-642.

Pascual, B., San Bautista, A., López-Galarza, S., Alagarda, J. and Maroto, J.V. (2006). Germination behaviour after storage of caper seeds. Seed Science and Technology, 34, 151-159.

Rinaldelli, E. (2000). Effect of ultrasonic waves on seed germination of Capparis spinosa L. as related to exposure time, temperature and gibberellic acid. Advances in Horticultural Science, 14, 182-188.

Rivera, D., Inocencio, C., Obón, C. and Alcaraz, F. (2003). Review of food and medicinal uses of Capparis L. subgenus Capparis (Capparidaceae). Economic Botany, 57, 515-534.

Rodrigo, M., Lázaro, M.J., Alvarruiz, A. and Giner, V. (1992). Composition of capers (Capparis spinosa): influence of cultivar, size and harvest date. Journal of Food Science, 57, 1152-1154.

SAS Institute (1989). SAS/STAT User's guide. Ver. 6. SAS Institute Inc., Cary, North Carolina.

Sozzi, G.O. and Chiesa, A. (1995). Improvement of caper (Capparis spinosa L.) seed germination by breaking seed coat-induced dormancy. Scientia Horticulturae, 62, 255-261.

Tansi, S. (1999). Propagation methods for caper (Capparis spinosa L.) seeds. Agricoltura Mediterranea, 23, 45-49.

Tei, F. and Ciriciofolo, F. (1997). Effect of simulated moisture stress on the germination of four crucifers. Sementi Elette, 43, 53-60.

Torres, M. and Frutos, G. (1989). Analysis of germination curves of aged fennel seeds by mathematical models. Environmental and Experimental Botany, 29, 400-415.

Torres, M. and Frutos, G. (1990). Logistic function analysis of germination behaviour of aged fennel seeds. Environmental and Experimental Botany, 30, 383-390.

Yildirim, Z. (1998). Studies on the improvement of seed germination in caper. Turk Journal of Field Crops, 3, 21-24.

Yili, A., Tao, W., Sagdullaev, T., Aisa, H.A., Ul'chenko, N.T., Glushenkova, A.I. and Rakhmanberdyeva, R.K. (2006). Lipids and carbohydrates from Capparis spinosa roots. Chemistry of Natural Compounds, 42, 100101. 